\title{
Results of a Rehabilitation Program After Surgery of Knee Multiple Ligament Injury: A Case Report
}

\section{Diz Çoklu Băg Yaralanmasında Cerrahi Sonrası Rehabilitasyon Programının Sonuçları: Olgu Sunumu}

\author{
Mesut Ergan ${ }^{1}$, Zeliha Başkurt ${ }^{1}$, Cem Çetin², Tolga Atay ${ }^{3}$ \\ ${ }^{1}$ School of Physiotherapy and Rehabilitation, Süleyman Demirel University, Isparta, Turkey \\ ${ }^{2}$ Sports Medicine Department, Faculty of Medicine, Süleyman Demirel University, Isparta, Turkey \\ ${ }^{3}$ Orthopaedics and Traumatology Department, Faculty of Medicine, Süleyman Demirel University, Isparta, Turkey
}

M. Ergan iD
$0000-0002-9712-5154$
Z. Başkurt iD
0000-0001-7488-9242
C. Çetin (D)
0000-0002-8151-9554
T. Atay iD
0000-0002-1429-9109

Geliş Tarihi/Date Received: 27.11.2018

Kabul Tarihi/Date Accepted: 06.01.2019

Yayın Tarihi/Published Online: 05.03.2019

Yazışma Adresi /

Corresponding Author:

Mesut Ergan

Süleyman Demirel Üniversitesi, Fizyoterapi ve Rehabilitasyon Bölümü, Isparta, Türkiye

E-mail:

mesuterganftr@gmail.com

(C)2019 Türkiye Spor Hekimleri Derneği. Tüm hakları saklıdır.

\begin{abstract}
Many anatomical structures contribute to knee stability. Four important ligaments (anterior cruciate ligament, posterior cruciate ligament, medial collateral ligament, and lateral collateral ligament) are the most important stabilizers of the knee. Multiple ligament injury is the tear of two or more large knee ligaments and results in multidirectional instability and knee laxity. After multiple ligament injuries, morbidity rate is high, and patients may complain of instability and pain even years following the injury. The aim of this study was to determine the effectiveness of a rehabilitation program applied to a patient who had undergone surgery after multiple ligament injury. Stability tests, universal goniometer measurements, Visual Analogue Scale, isokinetic testing, manual muscle test, Lysholm Knee Score and IKDC (Knee Documentation Committee) 2000 Knee Rating Score were used to assess the patient. The specified treatment program was applied in the first six months, three days a week and each session lasted about $60 \mathrm{~min}$. The evaluation process was completed in the form of face-to-face interview and exercise control, once a month for the next six months. At the end of the treatment, no serious deficit or instability remained in the knee, and the rehabilitation program was completed successfully.
\end{abstract}

Keywords: Multiple ligament injury, knee, rehabilitation

öz

Diz stabilitesine birçok anatomik yapı katkıda bulunmaktadır. Dört önemli bağ (ön çapraz bağ, arka çapraz bağ, medial kollateral bağ ve lateral kollateral bağ) dizin en önemli stabilizatörleridir. Çoklu bağ yaralanması, iki ya da daha fazla büyük diz bağının kopması durumudur. Bu yaralanma çok yönlü instabilite ve diz laksitesi ile sonuçlanır. Çoklu bağ yaralanması sonrası morbidite oranı yüksektir ve hastalar yaralanmadan yıllar sonra bile instabilite ve ağrıdan şikayet edebilmektedir. Bu çalışmanın amacı, çoklu bağ yaralanması sonrası cerrahi tamir yapılan bir olguya uygulanan rehabilitasyon programının etkinliğini belirlemektir. Hastanın değerlendirmesi için stabilite testleri, üniversal gonyometre ölçümü, Görsel Analog Skala, izokinetik test sistemi, manuel kas testi, Lysholm Diz Skoru ve IKDC (International Knee Documentation Committee) 2000 Diz Değerlendirme Skoru kullanıldı. Belirlenen tedavi programı ilk altı ay boyunca, haftanın üç günü ve her seans ortalama $60 \mathrm{dk}$ olacak şekilde uygulandı. Değerlendirme süreci sonraki altı ay boyunca ise ayda bir kere yüz yüze görüşme ve egzersiz kontrolü yapılarak tamamlandı. Tedavi sonunda olgunun dizinde ciddi bir defisit ya da instabilite görülmedi ve rehabilitasyon programı başarı ile tamamlandı.

Anahtar Sözcükler: Çoklu bağ yaralanması, diz, rehabilitasyon 
Available at: http://journalofsportsmedicine.org and http://dx.doi.org/10.5152/tjsm.2019.133.

Cite this article as: Ergan M, Baskurt Z, Cetin C et al. Results of a rehabilitation program after surgery of knee multiple ligament injury: A case report. Turk J Sports Med. 2019;54(3):202-6.

\section{GíRiş}

Çoklu bağ yaralanması (ÇBY), iki ya da daha çok büyük diz bağının kopması durumudur durumudur.Bu yaralanma, çok yönlü instabilite ve diz laksitesi ile sonuçlanır (1,2). ÇBY genellikle motorlu araç kazaları ya da ciddi spor yaralanmaları gibi yüksek enerjili travmaların sonucunda ortaya çıkmaktadır ve genellikle diz dislokasyonu eşlik etmektedir (1,3). Bu yaralanmalar yüksek tahribat oluşturarak dizlerde; bağ, kapsül, tendon, menisküs, kıkırdak yüzeyi, kemik, sinir ve kan damarı gibi yapılarda ciddi yaralanmalara neden olabilir (2). ÇBY'yi takiben morbidite oranı yüksektir ve hastalar yaralanmadan yıllar sonra bile instabilite ve ağrıdan şikayet edebilmektedir (3). Tüm ortopedik yaralanmalar içerisinde ÇBY insidansının \%0.02' den daha az olduğu belirtilmektedir $(1,3,4)$.

Çalışmalarda tedavi algoritmaları ve sonuçları bildirilmiştir ancak, çalışmalar küçük örneklemli ve retrospektiftir. Sadece birkaç prospektif çalışma yayınlanmış olup, bugüne kadar kompleks diz yaralanmaları için en uygun tedavi yöntemini araştıran randomize kontrollü çalışma yoktur (5). ÇBY tedavisi çalışmalarında kanıtlar yetersizdir ve bu nedenle cerrahlar kararsızlık yaşarlar. ÇBY'nin ameliyatsız tedavisinin kısa ve uzun vadeli sonuçları genellikle kötüdür. Bu nedenle çoğu hekim cerrahiyi tercih etmektedir (4). Owens ve ark. (6) erken cerrahiyi takiben modern bir rehabilitasyon programı uygulanmayan hastaların tedavi sonuçlarının başarısız olduğunu belirtmiștir.

Literatüre bakıldığında ÇBY sonrası tedavide özellikle cerrahi üzerinde durulmuş, ancak rehabilitasyon programları ayrıntılı paylaşılmamış ve rehabilitasyonda dikkat edilecekler konusunda ortak bir sonuç çıkarılamamıştır. Bu çalışmanın amacl, ÇBY sonucu cerrahi gören hastaya uygulanan rehabilitasyon programının etkinliğini belirlemektir.

\section{OLGU SUNUMU}

On altı yaşındaki erkek hasta tarım aletiyle yaralanma nedeniyle diş merkezden Araștırma ve Uygulama Hastanesi Ortopedi polikliniğine sevk edilmişti. Sol dizinde hareket kısitlılığı, şiddetli ödem, ağrı ve stabilite problemi bulunan hastaya radyolojik ve klinik değerlendirme ile birlikte ÇBY (ÖÇB, AÇB, MKB) tanısı konuldu. Hastada nörovasküler defisit yoktu. Ödemi azaldıktan sonra cerrahi ile artroskopik ÖÇB, AÇB rekonstrüksiyonu ve MKB onarımı yapılan hasta fizyoterapi programına alındı. Hastanın vücut ölçüleri (boy: $170 \mathrm{~cm}$, vücut ağırlığı: $83 \mathrm{~kg}$, vücut kütle indeksi: $28.7 \mathrm{~kg} / \mathrm{m}^{2}$ ) olarak belirlendi. Özgeçmişinde herhangi bir cerrahi operasyon ya da travma öyküsü yoktu. Hasta günde bir paket sigara kullanmaktaydı. Sunulan olgu ve ailesi yayın için bilgilendirildi ve onamları alındı.

Stabilite testleri (Lachman, ön çekmece, arka çekmece ve valgus stres testleri) cerrahi öncesi ve sonrası dönemde yapıldı. Hastanın ağrısını değerlendirmek için, Görsel Analog Skala (GAS) kullanıldı (7). Eklem hareket açıklığı üniversal gonyometre ile, kas kuvveti manüel kas testi ile değerlendirildi. Altıncı aydan sonra kas kuvveti değerlendirmesine izokinetik test eklendi. Hastanın cerrahi öncesi ve sonrasındaki klinik değerlendirmeleri için Lysholm Diz Skoru ve IKDC (International Knee Documentation Committee) 2000 Diz Değerlendirme Skoru kullanıldı. Tegner ve Lysholm tarafından geliştirilen ve sekiz parametre (aksama, destek, kilitlenme, instabilite, ağrı, şişlik, merdiven, çömelme) değerlendiren skor, tüm diz yaralanmalarında kullanılmaktadır. Bu skor hesaplanırken her parametrede en uygun seçenek işaretlenir ve bütün parametreden elde edilen puanlar toplanarak toplam skor bulunur. Lysholm diz skorunda; $\geq 95$ puan 'mükemmel', 84-94 puan 'iyi', 65-83 puan 'orta', $\leq 64$ puan 'kötü' olarak değerlendirilmektedir (8). Lysholm diz skorunun Türkçe geçerlik, güvenilirlik ve 
kültürel adaptasyonu çalışması Çelik ve ark. (9) tarafından yapılmıştır.

IKDC 2000 skorlaması ise diz yaralanmaları sonrası uygulanan tedavinin semptom ve fonksiyonlarda ne düzeyde gelişmeler sağladığını belirleyebilmek için kullanılmaktadır. Skorlama; semptomlar, günlük yaşam ve spor sırasındaki fonksiyon, dizin anlık fonksiyonu ile is ve spora katılımı içeren 18 maddeden olușmaktadır. Skorun yüksek olması; fonksiyonun yüksek, semptomların düşük seviyede olduğu anlamına gelir (10).

Hastanın değerlendirmeleri cerrahi öncesi, cerrahi sonrası 1. gün, 1.-3.-6. ve 12. ay olacak şekilde yapıldı. Değerlendirmeler sonucunda elde edilen veriler Tablo 1'de gösterilmektedir. Tedavi programı, hastanın günlük yolculuk zorunluluğu göz önünde bulundurularak altı ay boyunca haftanın üç günü ve her seans ortalama $60 \mathrm{dk}$ olacak şekilde, daha sonraki altı ay boyunca ise ayda bir kere yüz yüze görüşme ve egzersiz kontrolü şeklinde yapılarak tamamlanmıştır. Hastanın tedavisinde Wisconsin Üniversitesi Sağlık ve Spor Rehabilitasyonu bölümünün Çoklu Bă̆ Yaralanmaları Onarım Sonrası Rehabilitasyon Protokolü takip edilmiștir (5).

Tablo 1. Hastanın değerlendirme sonuçları

\begin{tabular}{|c|c|c|c|c|c|c|c|}
\hline & & CÖ & CS 1. gün & CS 1. ay & CS 3 .ay & CS 6. ay & CS 12. ay \\
\hline \multirow{4}{*}{ Sol diz EHA $\left(^{\circ}\right)$} & F-A & 20 & - & 50 & 100 & 125 & 125 \\
\hline & F-P & 30 & - & 60 & 120 & 135 & 130 \\
\hline & E-A & 05 & - & 05 & 00 & 00 & 00 \\
\hline & E-P & 00 & 00 & 00 & 00 & 00 & 00 \\
\hline \multirow{2}{*}{ Çevre ölçümü (cm) } & Sağ & 39.0 & 39.0 & 39.0 & 39.0 & 39.5 & 39.5 \\
\hline & Sol & 42.0 & 44.0 & 43.2 & 42.4 & 41.5 & 40.0 \\
\hline \multirow{2}{*}{ KK (sol) } & Q & - & - & $2^{+1 / 2}$ & 4 & 5 & 5 \\
\hline & $\mathrm{H}$ & - & - & $2+1 / 2$ & 3 & 4 & $4^{+}$ \\
\hline \multirow{2}{*}{ KK (sağ) } & Q & $4^{+}$ & $4^{+}$ & 5 & 5 & 5 & 5 \\
\hline & $\mathrm{H}$ & $4^{+}$ & $4^{+}$ & $4^{+}$ & 5 & 5 & 5 \\
\hline \multirow{2}{*}{ GAS $(\mathrm{cm})$} & Akt & 5 & 7 & 4 & 3 & 2 & 0 \\
\hline & İst & 3 & 6 & 4 & 1 & 0 & 0 \\
\hline \multirow{2}{*}{ Patellar mobilite } & Sağ & Normal & Normal & Normal & Normal & Normal & Normal \\
\hline & Sol & Hipomobil & Hipomobil & Normal & Normal & Normal & Normal \\
\hline \multirow{2}{*}{ İzokinetik test } & & & & & & Qd: \% 22 & Qd: \% 8 \\
\hline & & & & & & Hd: \% 32 & Hd: \% 17 \\
\hline 2000 IKDC skoru & & 16.0 & 16.0 & & 56.3 & 74.7 & 83.9 \\
\hline Lysholm skoru & & 07 & 07 & 28 & 58 & 82 & 89 \\
\hline Lachman testi & & $(+++/-)$ & & & & $(+/-)$ & $(+/-)$ \\
\hline Ön çekmece testi & & $(+++/-)$ & & & & $(+/-)$ & $(+/-)$ \\
\hline Arka çekmece testi & & $(++/-)$ & & & & $(-/-)$ & $(-/-)$ \\
\hline Valgus stres testi & & $(++/-)$ & & & & $(-/-)$ & $(-/-)$ \\
\hline
\end{tabular}

CÖ: cerrahi öncesi; CS: cerrahi sonrası; EHA: eklem hareket açılığı; KK: kas kuvveti; F: fleksiyon, E: ekstansiyon; A: aktif, P: pasif; -: değerlendirilemedi; Q: quadriceps, H: hamstring, d: defisit; Akt: aktivitede, İst: istirahat halinde. Çevre ölçümü patella orta noktasından alındı.

Oniki aylık tedavi ve izlem sürecinin sonunda hastanın kas kuvveti ve eklem hareket açıklığında belirgin bir artış olduğu gözlendi. Diz fleksiyonu yumuşak doku katlantıları nedeniyle her iki dizde de $135^{\circ}$ de son bulmaktaydl. Sağlam taraftaki $0^{\circ}$ lik ekstansiyonla birlikte bu değerler aktif ve pasif durumlarda çalıșma boyunca değişmedi. Sağlam tarafla kıyasla, aktif 
harekette $10^{\circ}$ 'lik limitasyon bulunurken; bu limitasyon pasif hareketle $5^{\circ}$ ye düştü. GAS ile yapılan ağrı değerlendirmesine göre hastanın ağrısı ortadan kalktı. Ancak, ağır yükler taşıyarak gün boyu çalıştığı dönemde gece GAS'a göre 3 düzeyinde ağrısının olduğunu; istirahat edince geçtiğini belirtti. Hastanın Lysholm Diz Skoru 'kötü' düzeyinden 'iyi' düzeyine yükselirken, IKDC 2000 skoruna göre ise fonksiyonelliği 67.9 puan artış gösterdi. Son değerlendirmesinde herhangi bir yürüyüş problemine rastlanmadı.

\section{TARTIŞMA}

Bu yazıda tartışılan olgu çoklu bağ yaralanması sonrası cerrahi geçirmiş hasta rehabilitasyon programına ve uzun süreli izlemine örnek oluşturmaktadır. Sunulan olgunun ağrısı tedavi sürecinin başlarında azaldı, sürecin sonunda ise çok ağır aktiviteler sonunda nadiren gelişen hafif şiddetli ağrı dışında hiçbir ağrısı kalmadı. Pasif eklem hareket açıklığında sağlam tarafla kıyasla $5^{\circ}$ limitasyon kaldı. Hasta sadece dizlerinin üstüne oturmakta biraz zorluk yaşamaktadır. Kas kuvveti kademeli olarak artış gösterdi. Olgu, uygulanan rehabilitasyon sonucunda iş ve spor yaşantısına geri dönmüștür.

Cerrahi prosedürlerin değişkenlik göstermesi; rehabilitasyon protokollerinin zamanlaması ve içeriğini araştıran çalışmaların görece azlığına neden olur. Sonuçta, konu tam anlaşılamamıştır ve yoğun tartışma konusu olmaya devam etmektedir. Cerrahi sonrası erken hareket ve ağırlık aktarma; yeniden yapılandırılan veya onarılan dokuların iyileşmesini ve uzun süreli eklem stabilitesini olumsuz yönde etkilediği düşünülürse, birey için risk oluşturmaktadır (11). Bununla birlikte, bazı araștırmacılar skar dokusunun eklem hareketini sinırlamasını önlemek ve kas atrofisini azaltmak için erken hareketi önermektedir (12). Kopma riskinden korunma ile hareket kaybı önlenmesi arasındaki denge sıklıkla aşırı korumayı desteklemekte ve bu durum potansiyel olarak daha fazla hareket kaybına neden olmaktadır (2). ÇBY ameliyatı sonrası koruma, cerrahi olarak onarlan veya yeniden yapılandırılmış dokuların iyileşmesi için önemlidir, ancak büyük yaralanmalar ve karmaşık ameliyatlar diz ekleminde sertlik, hareket kaybı ve artrofibrozis geliştirebilir.

Klinik araştırmaların sistematik olarak gözden geçirildiği bir çalışmadan elde edilen sonuçlara göre erken mobilite; diz stabilitesi, eklem hareket açıklığı ve fleksiyon-ekstansiyon limitasyonları açısından immobilizasyona göre daha iyi sonuç vermektedir. Lysholm skoru erken mobilizasyon grubuna (82 puan) kıyasla immobilizasyon grubunda (87.5 puan) bir miktar yüksek olsa da, istatistiksel anlamlılık ortaya koymamaktadır (13). Fanelli ve ark. (14), kompleks diz rekonstrüksiyonu sonrası terminal fleksiyon hareketinde $10^{\circ}-15^{\circ}$ kayıp olabileceğini belirtmişlerdir.

Bu sonuçlar, rehabilitasyonun mobilite bileşenine özeldir; zira "erken hareketlilik", ameliyat sonrası üç hafta içinde $30^{\circ}$ 'den fazla diz hareketi olarak tanımlanmaktadır. ÇBY ameliyatı sonrası erken hareketlilik ve ağırlık aktarmayı katı bir immobilizasyon protokolüyle karşılaştırmak gerçekçi değildir. Çünkü, birçok çalışma hala ekstansiyonda üç haftaya kadar immobilizasyonu savunmaktadır (2).

Birçok çalışmada, ÇBY cerrahisinden 4-6 hafta sonrasına kadar ekstremite üzerine ağırlık aktarılmaması önerilmektedir $(6,15)$. Çok az protokolde tolerans içinde ağırlık aktarma önerilirken (16), bazı çalışmalarda ise kısmi ağırlık aktarma (17) ya da parmak ucu dokunarak ağırlık aktarma önerilmiştir (18). Çalışmamızda hastaya literatüre uygun olarak ve cerrahın önerisi doğrultusunda ilk üç hafta immobilizasyon ve altı hafta ağırlık vermeden mobilizasyon protokolü uygulanmıştır.

Sabit bisiklet gibi düşük etkili aktiviteler cerrahinin 6-12. hafta sonrasında başlatılabilir. Dirençli hamstring egzersizlerinin, AÇB yaralanmalarının ve/veya diğer posterior yapıların (posterolateral köşe, hamstring, eklem kapsülü) tutulumuna bağlı olarak 8-16. hafta arasında başlatılması gerektiği bildirilmiştir. Koşu gibi etkinliklerin başlatılma süreci 3 ay ile 10. ayın sonu arasında değişmektedir. Tam aktiviteye dönüş genellikle ameliyattan itibaren 8-12 ay arasındadır (2). ÇBY sonrası spora dönüş \%17-81 arasında, ortalama \%50; ișe dönüș ise \%54-92 arasında, ortalama \%81'dir (19). ÇBY ameliyatından iki yıl 
sonrasinda dahi hem quadriceps hem de hamstringlerde önemli kuvvet yetersizlikleri olduğu bildirilmektedir (20).

Literatürde farklı görüşler ve protokoller belirtilmiş ancak optimal bir tedavi programı bildirilmemiştir. Çalışmamıza katılan olguda güvenli bir şekilde ilerleme sağlayabilmek için protokollerde belirtilen zaman aralıklarının genellikle orta ve son dönemlerinde gerekli uygulamalar yapılmıştır. Olgu daha öncesinde çalıştığı işine geri dönmüş; ancak sakatlanma ve ağrı korkusu nedeniyle ileri düzeyde sportif aktivitelerden kaçınmaktadır. Benzer çalışmalarda belirtildiği gibi, olgumuzda da 12 ay sonraki izokinetik testlerde bile hamstring kuvvet defisitinin devam ettiği görüldü. Ancak sonuç itibari ile değerlendirildiğinde, dizde ciddi bir defisit ya da instabilite görülmedi ve rehabilitasyon programı başarı ile sonuçlandırıldı. $\mathrm{Bu}$ sonuçlarda hastanın genç olmasının, tedavi ve görüşmelerin aksatılmadan sürdürülmesinin etkili olduğunu düşünmekteyiz.

\section{SONUÇ}

ÇBY cerrahisi sonrası uygulanan doğru rehabilitasyon programı tedavinin başarısını arttırmaktadır. Bu çalışma tek bir olgu üzerinden yürütüldügü için sonuçları genellemek mümkün değildir. Daha fazla bireyin katıldığı ve hareket korkusu gibi etkenlerin de değerlendirildiği yeni randomize kontrollü çalışmalara ihtiyaç vardır.

\section{KAYNAKLAR}

1. Wyatt RWB, Inacio MCS, Bellevue KD, et al. Isolated ACL versus multiple knee ligament injury: associations with patient characteristics, cartilage status, and meniscal tears identified during ACL reconstruction. Phys Sportsmed. 2017;45(3):323-28.

2. Lynch AD, Chmielewski T, Bailey L, et al. Current concepts and controversies in rehabilitation after surgery for multiple ligament knee injury. Curr Rev Musculoskelet Med. 2017;10(3):328-45.

3. Levy BA, Dajani KA, Whelan DB, et al. Decision making in the multiligament-injured knee: an evidence-based systematic review. Arthroscopy. 2009;25(4):430-8.

4. Hua X, Tao H, Fang W, et al. Single-stage in situ suture repair of multiple-ligament knee injury: a retrospective study of 17 patients (18 knees). BMC Musculoskelet Disord. 2016;17:41.

5. University of Wisconsin. Rehabilitation guidelines for knee multi-ligament repair/reconstruction. https://www.
uwhealth.org/files/uwhealth/docs/pdf5/MultiLigament.pdf (access 10.01.2017).

6. Owens BD, Neault M, Benson E, et al. Primary repair of knee dislocations: results in 25 patients (28 knees) at a mean follow-up of four years. J Orthop Trauma. 2007;21(2):92-6.

7. Bijur PE, Silwer W, Gallagher EJ. Reliability of the Visual Analog Scale for measurement of acute pain. Acad Emerg Med. 2001;8(12):1153-7.

8. Tegner Y, Lysholm J. Rating systems in the evaluation of knee ligament injuries. Clin Orthop Relat Res. 1985; 198:43-9.

9. Celik D, Coşkunsu D, Kiliçoğlu O. Translation and cultural adaptation of the Turkish Lysholm Knee Scale: ease of use, validity, and reliability. Clin Orthop Relat Res. 2013; 471(8):2602-10.

10. Anderson AF, Irrgang JJ, Kocher MS, et al. The International Knee Documentation Committee Subjective Knee Evaluation Form: normative data. Am J Sports Med. 2006;34(1):128-35.

11. Fanelli GC. Posterior cruciate ligament rehabilitation: how slow should we go? Arthroscopy. 2008;24(2):234-5.

12. Hubert MG, Stannard JP. Surgical treatment of acute and chronic anterior and posterior cruciate ligament and medial-side injuries of the knee. Sports Med Arthrosc Rev. 2011;19(2):104-9.

13. Mook WR, Miller MD, Diduch DR, et al. Multiple-ligament knee injuries: a systematic review of the timing of operative intervention and postoperative rehabilitation. J Bone Joint Surg Am. 2009;91(12):2946-57.

14. Fanelli GC, Stannard JP, Stuart MJ, et al. Management of complex knee ligament injuries. J Bone Joint Surg Am. 2010;92(12):2235-46.

15. Fanelli GC, Fanelli DG. Management of chronic combined PCL medial posteromedial instability of the knee. Sports Med Arthrosc Rev. 2015;23(2):96-103.

16. Görmeli G, Görmeli CA, Elmalı N, et al. Outcome of the treatment of chronic isolated and combined posterolateral corner knee injuries with 2- to 6-year follow-up. Arch Orthop Trauma Surg. 2015;135(10):1363-8.

17. Richter M, Bosch U, Wippermann B, et al. Comparison of surgical repair or reconstruction of the cruciate ligaments versus nonsurgical treatment in patients with traumatic knee dislocations. Am J Sports Med. 2002; 30(5):718-27.

18. Werner BC, Hadeed MM, Gwathmey FW Jr, et al. Medial injury in knee dislocations: what are the common injury patterns and surgical outcomes? Clin Orthop Relat Res. 2014;472(9):2658-66.

19. Peskun CJ, Whelan DB. Outcomes of operative and nonoperative treatment of multiligament knee injuries: an evidence-based review. Sports Med Arthrosc Rev. 2011;19(2):167-73.

20. Jenkins PJ, Clifton R, Gillespie GN, et al. Strength and function recovery after multiple-ligament reconstruction of the knee. Injury. 2011;42(12):1426-9. 